\title{
The Benefits of Use of Plastic Money in Greece and the EU: Case Study of Use of Plastic Money from the Elderly
}

\author{
Liargovas Panagiotis*, Anastasiou Athanasios, Komninos Dimitrios, Dermatis Zacharias, \\ Kalamara Eleni \\ Department of Economics, University of Peloponnese, Peloponnese, Greece \\ Email: *liargova@uop.gr
}

How to cite this paper: Panagiotis, L., Athanasios, A., Dimitrios, K., Zacharias, D. and Eleni, K. (2018) The Benefits of Use of Plastic Money in Greece and the EU: Case Study of Use of Plastic Money from the Elderly. Theoretical Economics Letters, 8, 793-805.

https://doi.org/10.4236/tel.2018.85055

Received: January 12, 2018

Accepted: March 24, 2018

Published: March 27, 2018

Copyright $\odot 2018$ by authors and Scientific Research Publishing Inc. This work is licensed under the Creative Commons Attribution International License (CC BY 4.0).

http://creativecommons.org/licenses/by/4.0/

\section{c) (i) Open Access}

\begin{abstract}
Plastic money is a very recent context replacing the traditional concept of paying though cash. Plastic money is a term coined keeping in view the increasing number of transactions taking place on the part of consumer for paying for transactions incurred by them to purchase goods and services physically and virtually. It includes credit cards, debit cards, pre-paid balance cards, smart cards etc. This research is typically focusing only on the use of debit cards from the elderly in order to find out the effectiveness of such cards in real life and consumers perceive them. It also presents the use of electronic wallet. Is electronic wallet helpful in every day's transactions? Can old age people find it helpful in using it? Electronic wallet accepts debit cards that are connected with the banking account which has been declared by elderly in the financial institution. It allows an individual person to purchase something at a store and enables unforgeable transactions with other wallets.
\end{abstract}

\section{Keywords}

Debit Card, Credit Card, Plastic Money, Old Age, Transactions, Financial Institutions

\section{Introduction}

More and more often, we are increasingly dependent on new technologies to make our transactions fast and efficient. The continued and rapid growth of technology has brought about significant changes in our everyday lives. During the last few months and due to the imposition of restrictions in the movement of banking capital, there is an enormous increase of internet banking transactions 
using the so called "plastic money" instead of cash. Plastic money is an alternative to the cash or the standard "money". Plastic money is referring to the credit cards or the debit cards that we use to make purchases. Plastic money is a very recent context replacing the traditional concept of paying though cash. Plastic money is a term coined keeping in view the increasing number of transactions taking place on the part of consumer for paying for transactions incurred by them to purchase goods and services physically and virtually. It includes credit cards, debit cards, pre-paid balance cards, smart cards etc [1].

Specifically, two weeks after the imposition of capital controls, and according to the data provided by the Bank of Greece, there was an increase in the transactions with the use of cards, which exceeded $135 \%$.

The same tendency exists for the use of both credit and debit cards. According to the Institution of Trade and Services and the National Confederation of Commerce and Entrepreneurship, in a bibliography for research surveying the current situation, it is mentioned that the use of "plastic money" in trade was tripled. According to the latest available data from credit institutions, from the end of June 2015, when bank holiday and capital controls were imposed and until the first day of August 2015, more than 1.1 million debit cards were issued in a month period of time, surpassing the 11 million of them as a total number, whereas before the start of capital controls the issued cards were less than 100,000 cards monthly.

The imposition of capital control matured the conditions for the use of electronic transactions. Payments through electronic transactions became part of consumer's every day's life routine. Thus, a favorable environment was created for the transition from cash transactions to electronic transactions using cards, contributing in this way the reduction of tax evasion and the increase of state's revenue. Nevertheless, a part of consumers, such as the elderly, face the electronic transactions and the use of plastic money, with mistrust. Therefore, the adaptation of older consumers in the new era of electronic payments is considered necessary using appropriate technology specialized to elderly people.

This research presents the necessity of using plastic money from the elderly and how the electronic payment method facilitates their daily transactions. The objective of this paper is to present the electronic wallet device to address the particularities of elderly.

Through the literature review and study of related research, it is difficult for elderly people to handle electronic payment management devices (computer, tablet, smart phone) for their daily personal needs. This difficulty is mainly due to lack of education, reduced vision and a sense of insecurity with new technologies. The new device presented is tailored to meet the needs of elderly people.

\section{To Which Categories of Elderly Is This Research Referring to}

It is very difficult to provide a satisfactory definition for a heterogeneous population like elderly, due to different ways of determining of elderly chronological- 
ly. The German politician Bismarck established arbitrarily in 1889 the 65 year of age as essential criterion for economic benefits from the social actuarial systems to the employees. In 1980 the UN mentioned that individuals +80 should be characterized as very old. During the "International Assembly of Old age" in 1982, it was mentioned that the term old man has the chronological limit of 60 years. However, it is generally acceptable that the age of 65 years remains the age of obligatory retirement.

Thus, our interest concerns:

- Elderly older than 65 years.

- Elderly who live in remote areas and in villages of less than 3000 in habitants.

\section{Literature}

It is no coincidence that there are few available studies on their use technologies in every day's transactions from older people. In other countries, the picture is completely different. In Germany, 2007, the percentage of users of new technologies aged 60 - 69 were $35.5 \%$ and above $70,13.2 \%$ [2]. In the Netherlands in 1998 in the age group 75+ had a 10\% mobile phone, a 75\% PIN and an electronic one $5 \%$ [3].

Many countries have undertaken training initiatives older people in new technologies, such as a funded project by Eldergames the EU to develop games using advanced imaging for improving the cognitive, functional and social skills of the elderly users [4].

In a survey conducted by the Information Society on New Technologies in Citizens' Daily Life and published in June 2014, some interesting results have been identified. Only $11.7 \%$ of the elderly people regularly use the internet at least once a week, with only $27.2 \%$ having home access to the internet, and only $19.5 \%$ are online shopping.

E-commerce is an important opportunity for the elderly to become independent, less socially isolated and more vulnerable [5].

The increase in the number of elderly in the coming years, raises concerns on how this vulnerable group will have quality life today. The technology gives the solution and led to the creation of products and programs that help the elderly cope with their problems in daily life.

In the region of Thessaly in Greece in the old people's homes and the Centers for Open Protection of the Elderly, in a sample of 384 people, 244 were men and 137 were women. $83.3 \%$ of the people were in the age group 75 - 84. Also, Centers for Open Protection of the Elderly constitute the most appropriate structure for training the elderly in the different forms of the young technology.

Studies that have been done, such as the MOBILATE 2000 database, where conducted a survey in 5 European countries, aimed at strengthening it independence of the elderly and the EUROSTAT survey in 2008 for its use mobile phones in 30 countries have been led to the conclusion that its use technology from the elderly depends on some factors such as levels health, educational level, 
income, place of residence, occupation followed when he was young and age. Technology respecting human existence, will lead to the improvement of the quality of life of the elderly in all levels ([6] [7]).

\section{Theoretical Background}

\subsection{Motivation for the Use of Electronic Transactions and Plastic Money}

Suitable motives could be adopted by the state which will function positively for the general acceptance of plastic money and electronic transactions. Some of these motives are:

- Reductions in both indirect taxes (VAT) and direct taxes (income taxes) when households and enterprises achieve targets by using plastic money in their daily transactions.

- Participation in prizes, gifts promotions and collection of marks (points). This motive is already applied with particular success in more than one third of EU countries hoping to convince people to use the plastic money for purchases of products and services. The marks (points) correspond to specific gifts, gift vouchers, discounts from specific stores or subsidization for the purchase of products for hygiene and personal care of the elderly.

- Return of a part of the value of the transaction for consumer's first need products, such as foods, clothing, locomotion etc. Specifically, in our country several financial institutions use cash back programs either directly to the consumer's account or in the form of cash back for purchases from certain stores.

\subsection{Profits from the Use of Plastic Money}

It has been realized that the increase of electronic transactions against those with cash is consistent with the increase of transparency in the transactions and helps in the reduction of tax evasion, since all electronic payments are identified more easily. Actually, according to the Report of the Institution of Economic and Industrial Researches [8], the increase of income taxes via the restriction of tax evasion plays also fundamental role in the effort of rationalization of public finances and return of Greek economy into development. In the Weekly Bulletin of Economic Evolutions of Alpha Bank, it is mentioned also that "the increased use of electronic payments at $10 \%$ annually on a time period of four continuous years could decrease the black economy up to 5\%". The same bulletin reports that "Greece continues presenting high level of black economy comparatively with other European countries", while it stresses that the use of credit cards could help in the fighting against black economy.

In Greece the number of cards per capita in 2015 was 1.3\%, while the percentage of black economy in the GNP, although it has been decreased progressively during the period of economic crisis, i.e. from $25.4 \%$ in 2010 to $22.4 \%$ in 2015 , still remains in high level in comparison with the corresponding European mean 
which is $18.3 \%$. Thus, the increase of the number of used cards per capita could contribute in the reduction of illegal transactions. This ensures also the avoidance of money laundering.

Moreover, it increases the collectability of VAT and helps the collection of taxes, since the avoidance of issuing transaction evidence, facilitated when the payment is made in cash and allows vendors not to deliver value added tax to the state. At the same time facilitates significantly the automation and control mechanism of taxes.

Electronic transactions minimize the required time of payment. The entire transaction does not exceed the 25 seconds and the process is not characterized by any difficulty. The payments of goods or services are carried out directly with debit of banking account of the consumer. The users are exempted from the risk of transactions errors occurring due to manual calculations carried out under the pressure of time either by the consumer or by the vendor.

Additionally, by electronic transactions, consumers will automatically obtain a statement of their annual family expenses, and their direct registration in the corresponding code of the consumer's Tax Statement. At the same time the use of auxiliary medical and nursing personnel from elderly, for their daily care, is simplified, since any transaction will be registered automatically in the corresponding code of medical expenses of their Tax Statement. Consequently, the income and the insurance contributions of auxiliary nursing personnel will be registered immediately in the state's informative systems increasing so the state's insurance contributions and the taxes revenues.

Finally, internet banking and use of cards will provide to elderly an additional security since there will be a reduction in thefts and robberies due to the lack of natural object. In point of fact it exempts the holder from the need of carrying cash and thus decreases the danger of losing money. Also, the danger of payments with counterfeit money is avoided, while the waiting in queues at ATMs which is particularly tiring especially for elderly is avoided also.

\subsection{Difficulties during Application of Electronic Transactions}

The main problem for elderly comes from the cost of acquisition of particular instrument for the realization of electronic transactions. The cost for electronic wallet should be subsidized from the state or from the financial institutions of our country, in order to be applied as a method of payment from most of the consumers, including elderly. At the same time, it is supposed that particular care will be taken for learning and change of mentality that imposes the use of new technology from elderly. Some essential processes for the adaptation of this new method of electronic banking are the publication of analytic instructions from the state's institutions, the publication of informative leaflets of use by the financial institutions and the creation of help desks to explain misunderstandings and to provide explanations to elderly for the new system of transactions. 


\section{Methodology-Experience from Using Plastic Money from the Elderly in EU Countries}

\subsection{Experience from Use in Greece}

Generally, and according to the Institution of Economic and Industrial Researches report (2015), there is a significant variation between Greece and other Eurozone countries in the use of plastic money. In the following chart of Figure 1 Greece holds the last place in the ranking in terms of number of transactions per inhabitant. Specifically, in Greece they held about 17 transactions per inhabitant, while in Luxembourg the figure stands at 2.596 transactions and in the EU 189 transactions take place.

Also, at the period of economic crisis, the use of plastic money shrank due to the high fall of private consumption as a result of the restricted limits of credit cards by the financial institutions. According to the report of the European Central Bank (ECB) [9], from the beginning of the economic crisis up to in 2014, the number of credit cards and the number of terminals in the Points of Sale (POS) were decreased progressively due to the reprocess of consuming expense resulting from the reduction of available income of households, as shown diagrammatically in the following Figure 2.

Regarding the percentage of transactions per means of transaction, with criterion the number of transactions in Greece during 2013, it is clear from the following diagram of Figure 3 that roughly the half of transactions via the banking system were realized via credit transfer ${ }^{1}$ (45.8\% in 2013 against $8.4 \%$ in 2000). The transactions with use of credit card were decreased dramatically $(26.5 \%$ in 2013 against $64.2 \%$ in 2000). This fall is explained due to the credit shrinkage

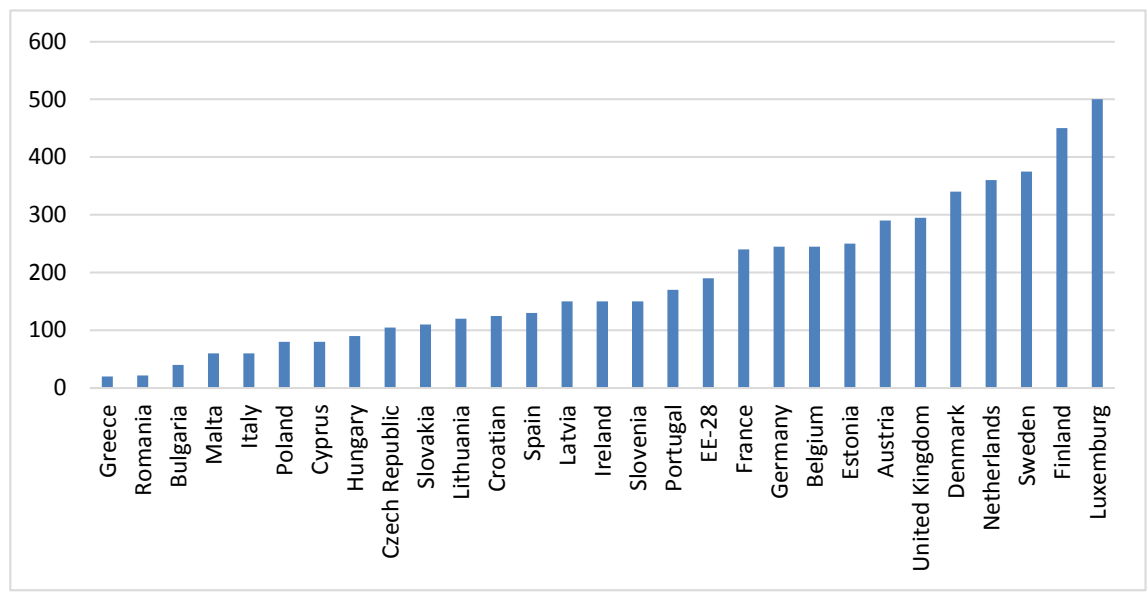

Figure 1. Number of transactions with electronic means of payment per resident (2013). Source: European Central Bank, Treatment: Institution of Economic and Industrial Researches.

${ }^{1}$ Credit transfer: Payment means by which the payer instructs his bank to transfer money to the beneficiary account. The orders and amounts transferred by the credit institution of the payer to the payee's credit institution may possibly be transferred through other credit institutions. As electronic payment instrument which is performed remotely, include transactions with online banking, which are directly operated by the payer with the use of a computer or mobile device. 


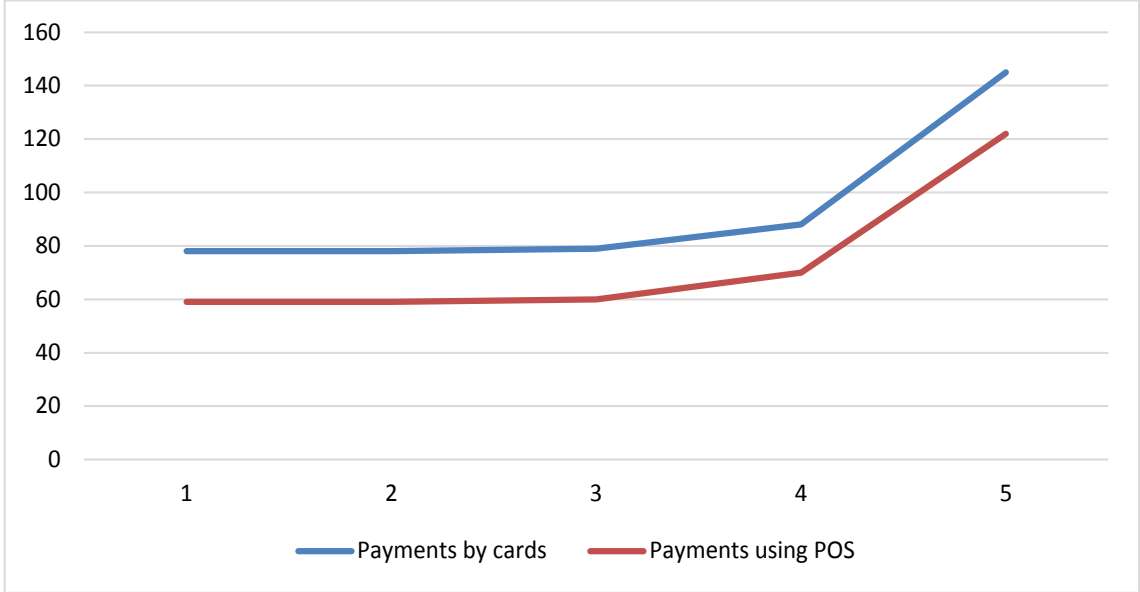

Figure 2. Number of Transactions Via Cards and Via Terminals in the Points of Sale-POS, (in millions). Source: ECB.

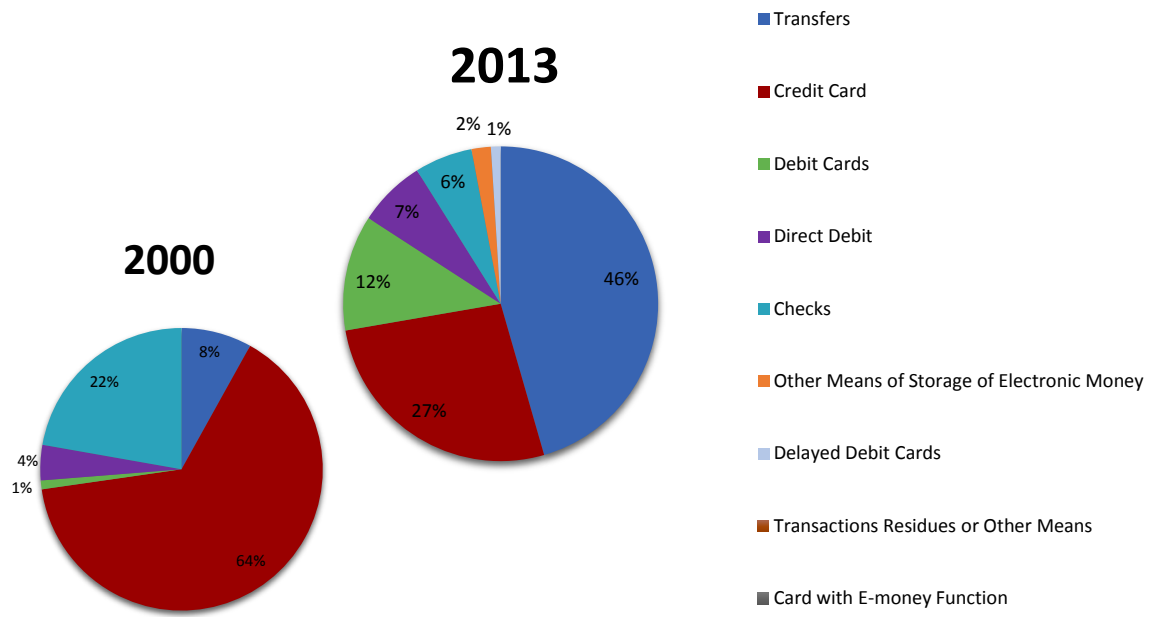

Figure 3. Percentage of transactions per means of transaction with criterion the number transactions, in Greece. Source: ECB.

during the years of economic crisis (2009-2013), but also due to increase in the use of the debit cards, (11.8\% in 2013 against $1.0 \%$ in 2000).

In Table 1, the use of the main payment services in the EU and the relative importance of the main payment services in the EU (2014) (percentages of total number of transactions) are presented.

Comparing the use of cards in Greece and the other countries of EU, from year 2000 until 2013, this research concludes that in 2013 Greece occupies the one before the last place as shown in the following diagrams of Figure 4 and Figure 5. The first country is Sweden with 250 transactions per resident, followed from Finland with 225 and the United Kingdom with 181, while in the last location after Greece is Bulgaria with 6 transactions per resident and before Greece is Romania with 9 transactions. It is remarkable that although Greece has a satisfactory number of debits and credit cards compared to the countries of $\mathrm{EU}$, their use is not extensive. 
Table 1. Use of the main payment services in the EU. Relative importance of the main payment services in the EU (2014) (percentages of total number of transactions). Source: FCB.

\begin{tabular}{|c|c|c|c|c|c|c|c|c|}
\hline & 2014 & $\begin{array}{c}\text { Change } \\
\text { from } 2013 \\
\text { (pp) }\end{array}$ & 2014 & $\begin{array}{c}\text { Change } \\
\text { from } 2013 \\
\text { (pp) }\end{array}$ & 2014 & $\begin{array}{c}\text { Change } \\
\text { from } 2013 \\
\text { (pp) }\end{array}$ & 2014 & $\begin{array}{c}\text { Change } \\
\text { from } 2013 \\
\text { (pp) }\end{array}$ \\
\hline Belgium & 39.80 & 2.00 & 15.40 & 3.80 & 43.90 & -5.40 & 0.10 & -0.10 \\
\hline Bulgaria & 61.20 & -19.00 & 1.80 & -0.40 & 20.70 & 3.00 & 0.00 & - \\
\hline Czech Republic & 47.30 & -3.00 & 11.80 & -1.70 & 40.10 & 4.90 & 0.00 & 0.00 \\
\hline Denmark & 16.70 & 0.00 & 10.00 & -1.40 & 73.20 & 1.40 & 0.10 & 0.00 \\
\hline Germany & 32.90 & 1.00 & 48.20 & -1.70 & 18.50 & 0.10 & 0.20 & 0.00 \\
\hline Estonia & 34.50 & 3.00 & 0.60 & -0.90 & 65.00 & -1.90 & - & - \\
\hline Ireland & 22.80 & 3.00 & 12.10 & -2.00 & 59.20 & 2.40 & 5.50 & -3.50 \\
\hline Greece & 55.60 & 10.00 & 4.80 & -2.40 & 34.70 & -4.40 & 3.60 & -2.00 \\
\hline Spain & 14.50 & -1.00 & 33.30 & -7.80 & 44.00 & 1.70 & 1.20 & -0.10 \\
\hline France & 18.00 & 0.00 & 18.70 & 1.50 & 49.80 & 0.20 & 13.10 & -1.40 \\
\hline Croatia & 44.50 & -11.00 & 3.10 & -0.60 & 33.40 & -6.90 & 0.00 & 0.00 \\
\hline Italy & 28.10 & 0.00 & 12.70 & -1.20 & 42.40 & 2.00 & 4.80 & -0.80 \\
\hline Cyprus & 18.60 & -13.00 & 33.00 & 26.60 & 34.40 & -10.30 & 12.80 & -3.60 \\
\hline Latvia & 41.40 & -5.00 & 1.30 & -0.20 & 57.20 & 6.20 & 0.00 & 0.00 \\
\hline Lithiania & 48.70 & -1.00 & 3.90 & -0.20 & 47.40 & 1.60 & 0.00 & 0.00 \\
\hline Luxembourg & 3.40 & -1.00 & 0.90 & -0.20 & 5.90 & -0.40 & 0.00 & 0.00 \\
\hline Hungary & 54.60 & -3.00 & 6.60 & -0.50 & 35.90 & 1.70 & 0.00 & 0.00 \\
\hline Malta & 21.90 & 1.00 & 3.70 & -2.40 & 49.10 & 0.20 & 24.70 & 0.40 \\
\hline Netherlands & 31.70 & 0.00 & 18.00 & -2.90 & 49.10 & 3.70 & 0.00 & 0.00 \\
\hline Austria & 34.10 & -5.00 & 29.20 & -7.00 & 36.20 & 13.80 & 0.10 & 0.00 \\
\hline Poland & 51.00 & -5.00 & 0.60 & -0.10 & 48.30 & 4.60 & 0.00 & 0.00 \\
\hline Portugal & 14.40 & 0.00 & 11.50 & -0.50 & 67.30 & 0.70 & 3.90 & -0.60 \\
\hline Romania & 45.60 & -1.00 & 2.10 & 0.00 & 51.80 & 2.20 & 0.50 & -1.10 \\
\hline Slovenia & 45.70 & 0.00 & 11.80 & -0.60 & 42.40 & 0.40 & 0.00 & 0.00 \\
\hline Slovakia & 51.30 & 2.00 & 4.80 & -9.40 & 43.80 & 7.50 & 0.00 & 0.00 \\
\hline Finland & 39.40 & -8.00 & 0.10 & -2.80 & 60.50 & 10.60 & 0.00 & 0.00 \\
\hline Sweden & 24.50 & 0.00 & 8.30 & -0.40 & 67.20 & 0.60 & 0.00 & 0.00 \\
\hline United Kingdom & 18.50 & -1.00 & 17.30 & -0.60 & 61.20 & 2.30 & 3.00 & -0.60 \\
\hline
\end{tabular}

Generally, in the European Union, from 2000 until 2014, the use of plastic money was increased, with an increase of $0.9 \%$ in 2014, reaching a total of 766 million transactions. This percentage represents roughly 1.5 card for plastic money per European citizen. The following diagram of Figure 6 presents graphically the use of main electronic payments as main payment services in the $\mathrm{EU}$ (number of transactions per year in billions, estimated). 


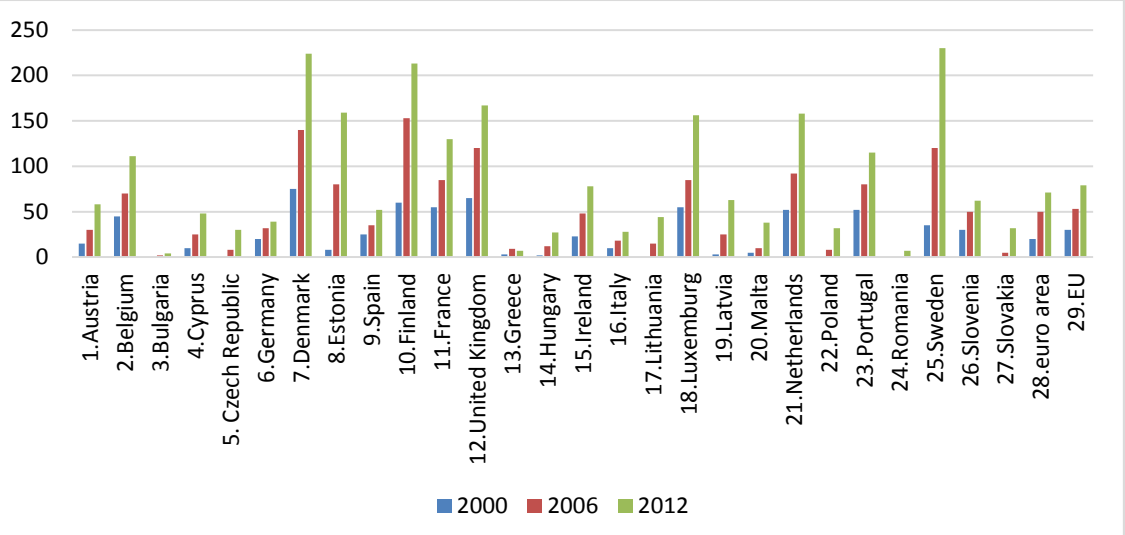

Figure 4. Number of card payments per inhabitant and per year. Source: ECB and the ECB's Statistical Data Warehouse.

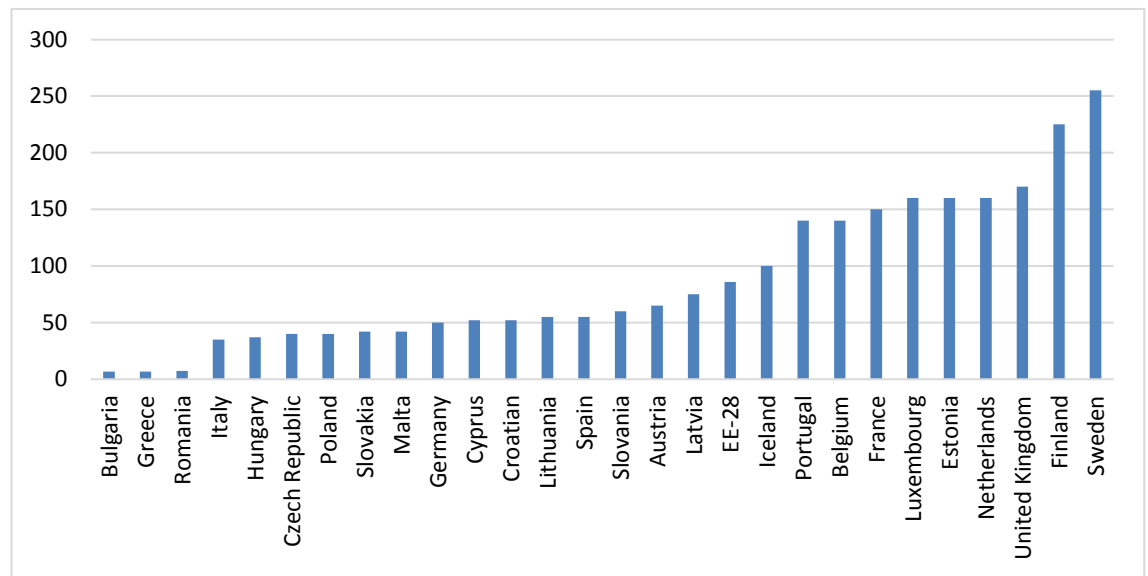

Figure 5. Number of transactions per resident with all types of cards (except the cards that concern electronic money) (2013). Source: ECB.

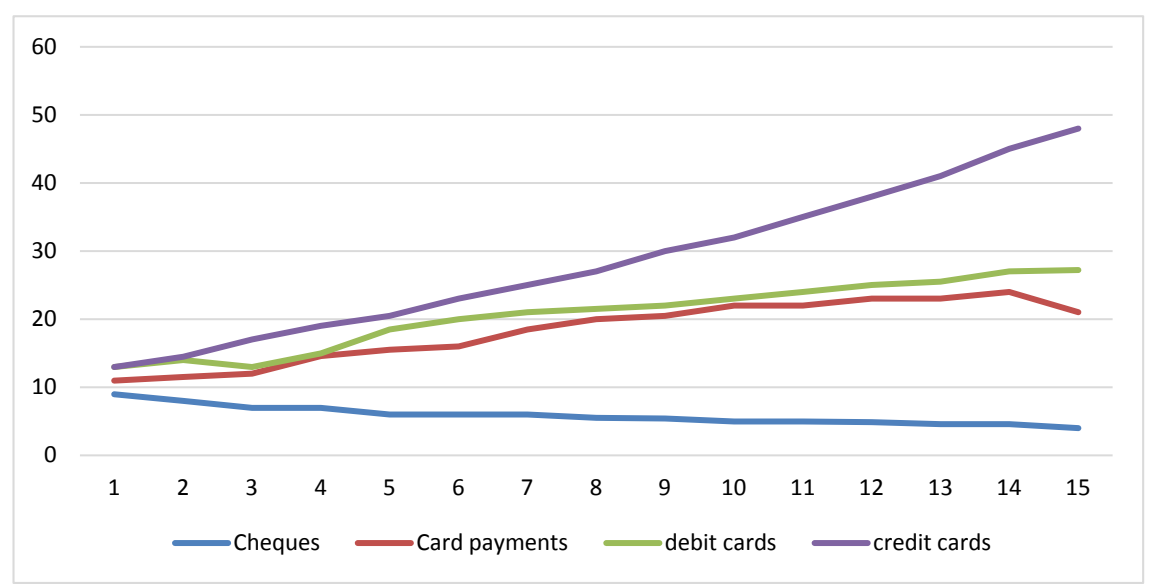

Figure 6. Use of the main payment services in the EU (number of transactions per year in billions, estimated). Source: ECB.

As for the age-related structure, it is clear from the diagram of Figure 7 that the use of credit cards is higher for the individuals of higher age, with a reverse 


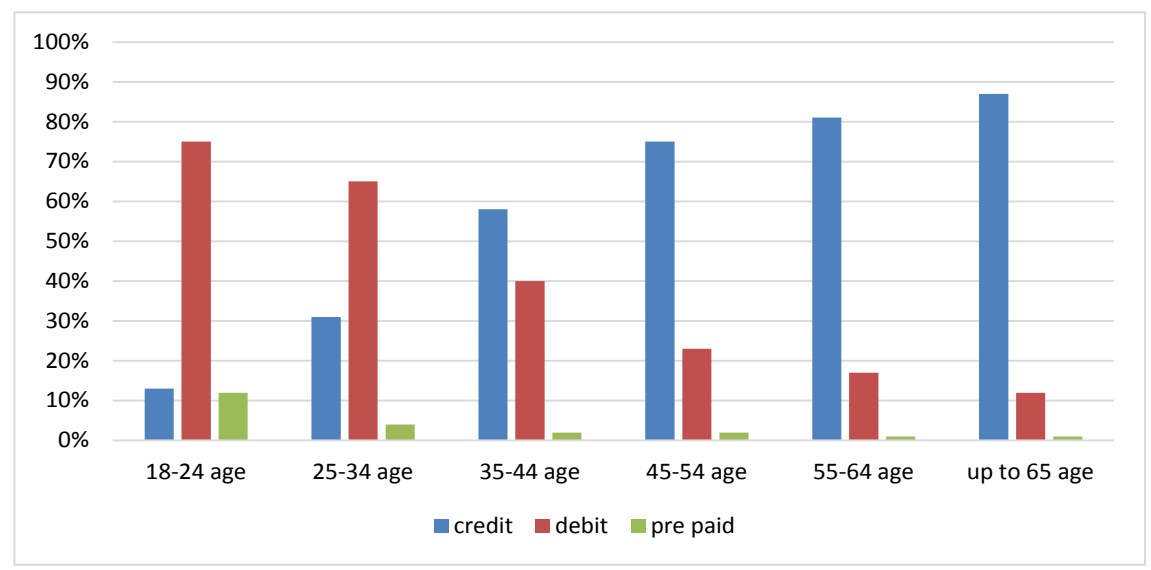

Figure 7. Type of cards used per age. Source: National Bank, Bank Piraeus, Alpha Bank and Eurobank, treatment of elements IOBE.

tendency for the debit cards. Consequently, the percentage of customers of more than 65 years old that uses credit card is at least 4 times higher comparative with the corresponding percentage of the customers of $18-24$ years [10], in their study mention that the use of debit cards is almost generic, touching according to them a percentage of $97 \%$, while the use of credit cards was almost $54 \%$, presenting an increase of $4 \%$ w.r.t. year 2004.

Pensioners, having increased needs which cannot be covered with cash money potentially select to transfer the refunding of their purchases through the use of credit card. It is a possibility which could not be achieved with debit cards (Figure 8).

\subsection{Presentation of Electronic Wallet for Elderly Daily Transactions}

Electronic wallet accepts debit cards that are connected with the banking account which has been declared by elderly in the financial institution. It allows an individual person to purchase something at a store and enables unforgeable transactions with other wallets. It is safer than cash money and it can replace credit-cards, checks and it also saves the paper work involved in their use [11]. The electronic wallet has both a software and information component. The software provides security and encryption for the personal information and for the actual transaction. The information component is basically a database of user-input information.

In the lower part of appliance there is an entrance slit for the debit card through which the appliance has a wireless communicates (NFC). Encryption of user's data is achieved by the SSL-256-bit protocol. The access of the user to the appliance is possible either with fingerprint or by typing of personal code. The appliance is drawn for android operating system. The user while making a transaction, it is automatically recorded so that elderly could check at any time all his transactions that he has made during the day. In the same time elderly have the possibility to check all his transactions and the balance of his account 


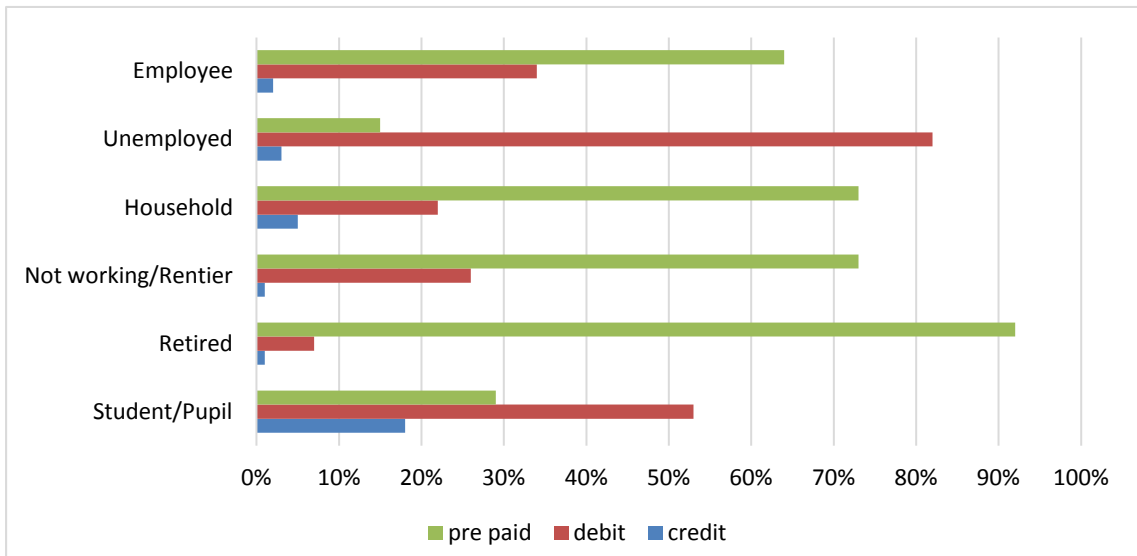

Figure 8. Good of cards used by per professional/economic situation. Source: National Bank, Bank Piraeus, Alpha Bank and Eurobank, treatment of elements IOBE.

for a certain period of time.

The use of the device is quite simple and easy to read by elderly users. The elderly using two buttons (left-right arrow) is transferred to the menu of the device from which he decides to present on the screen his transactions or the balance of his account. His bank account is linked to the electronic wallet. By this way there is a complete control from the part of the user to check his money availability for further transactions. At the top of the device there is a red light indicating to the elderly that he is approaching his lower account balance limit (Figure 9).

The implementation of the transaction is as follows: The elderly choosing the purchase a product or a service brings the electronic wallet close to the POS. The elderly then is informed by the device about his transactions and account balances after having entered his password or using his fingerprint. Then, if he wishes to continue with this transaction, he enters the same code to the POS. By this way, the transaction is completed and all required information are stored (such as supplier information, date and time, and total amount) in the electronic wallet.

The electric energy that supplies the appliance is obtained from an incorporated rechargeable Li-ion battery with roughly one-week duration. Consequently, this capacity covers the weekly transactions until it needs recharge. There is an optical indicator in the screen of the appliance providing the rate of battery charge.

\section{Conclusions}

From the results of this study, as well as the literature review, it is obvious that the use of new technologies by the elderly population significantly contributes to a better quality of life by improving the parameters of everyday life. The contribution of the innovative electronic trading device protects the elderly from theft and counterfeit cases as the device together with the card will be his wallet in 


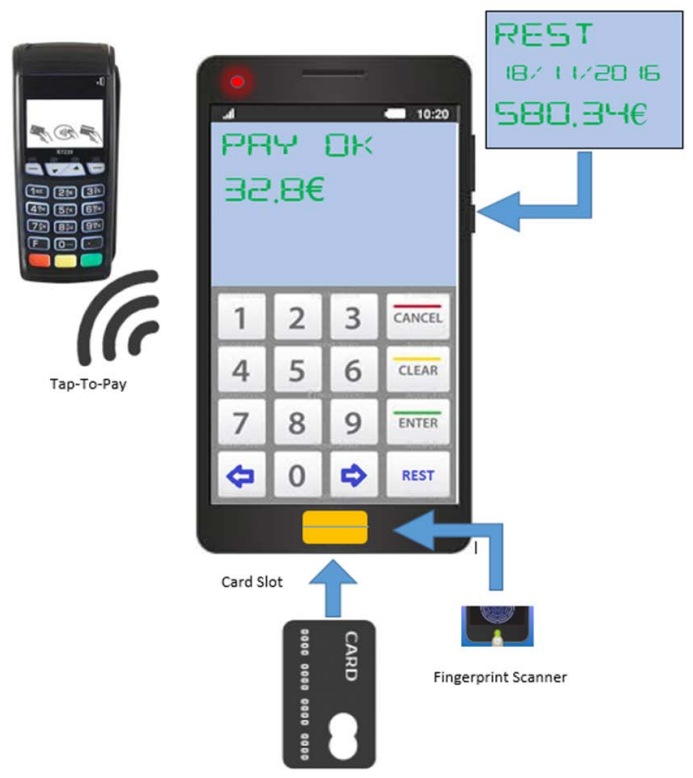

Figure 9. Use of electronic wallet.

every transaction with immediate information on the available balance of his account.

The previous presentation argues the necessity for widespread use of plastic money in the daily transactions of elderly. Electronic wallet takes into consideration all the particularities of third age achieving speed and security in their daily transactions and avoiding long waiting in the queue and the ATMs of the financial institutions for money withdrawal for their necessary expenses. Particular accent is given to elderly living in remote regions with lack of infrastructures, banks or ATMs.

The universal use of electronic wallet in all transactions will lead in:

- Reduction of administrative cost of services of mediation for transactions.

- Growth of new services adapted with individuals of third age.

- Improvement of effectiveness of commercial transactions system.

- Reduction of least $25 \%$ of "black" economy, strengthening state's revenues.

- Increase of competition in product and service markets

- Increase of consumption.

- Confrontation of phenomena of tax evasion and tax evaders.

\section{References}

[1] Bisht, A., Nair, P., Dubey, R. and Hajela, T. (2015) Analysis of the Use of Plastic Money: A Boon or a Bane. SIMS Journal of Management Research, 1.

[2] ICT4T (2013) Guidelines for the Education of Older People in New Technology. http://www.anchhells.org

[3] de Klerk, M. and Ouderen, R. (2001) veranderingen in deleefsituatie (Report of Older People 2001, Changes in Life Situation). The Hague: SCP 2001.

[4] Gamberini, L., Alcaniz, M., Barresi, G., Fabregat, M., Ibanez, F. and Prontu, L. (2006) Cognition, Technology and Games for the Elderly: An Introduction to 
ELDERGAMES Project. Psychnology Journal, 4, 285-308.

http://www.psychnology.org/File/PNJ4(3)/PSYCHNOLOGY_JOURNAL_4_3_GA MBERINI.pdf

[5] Shapira, N., Barak, A. and Gal. I. (2007) Promoting Older Adults' Well-Being through Internet Training and Use. Aging Mental Health, 11, 477-484.

https://doi.org/10.1080/13607860601086546

[6] Arsenos, P., Sapountzi-Krepia, D., Roupa, Z., Zafiri, V., Nikas, M., Darivakis, S. and Krepia, V. (2007) Aspects of Money Management in Elderly Populations: Views of Members of Open Care for the Elderly Centres on the Use Automatic Cash Machines (Acmes) of the Banks. Health Science Journal, 1-12.

http://www.hsj.gr/volume1/issue1/issue1_original_papers1.pdf

[7] Tacken, M., Marcellini, F., Mollenkopf, H., Ruoppila, I. and Széman, Z. (2005) Use and Acceptance of New Technology by Older People. Findings of the International MOBILATE Survey: "Enhancing Mobility in Later Life". Gerontechnology, 3, 126-137.

[8] Institution of Economic and Industrial Researches (IOBE) (2015) The Electronic Means of Payment and the Increase of Tax Income in Greece.

[9] European Central Bank (2015) Press Release.

[10] van der Cruijsen, C. and Plooij, M. (2015) Changing Payment Patterns at Point-of-Scale: Their Drivers.

[11] Even, S. and Golreich, O. (1984) Electronic Wallet. Springer Editions. 